\title{
A New Inhibitor for Steel Rebar Corrosion in Concrete: Electrochemical and Theoretical Studies
}

\author{
Youcef Bellal $^{1}$, Saida Keraghel ${ }^{1, *}$, Fatiha Benghanem $^{1}$, Toukal Linda ${ }^{1}$, Gökmen Siğırcık², \\ Bourzami Riadh ${ }^{3}$, Ali Ourari ${ }^{1}$ \\ ${ }^{1}$ Laboratory of Electrochemistry, Molecular Engineering and Redox Catalysis (LEIMCR) \\ Department of Engineering Process, Faculty of Technology, Ferhat Abbas University Setif-1, Setif, \\ Algeria \\ ${ }^{2}$ Chemistry Department, Faculty of Science and Letters, Çukurova University, Adana, Turkey \\ ${ }^{3}$ Emerging Materials Reaserch Unit, Ferhat Abbas University Setif -1, Setif, Algeria \\ *E-mail: s_marouani20012002@yahoo.fr
}

doi: $10.20964 / 2018.07 .91$

Received: 11 March 2018 / Accepted: 18 April 2018 / Published: 5 June 2018

\begin{abstract}
An original Schiff base 4-hydroxy-3-[1-(3-hydroxy-naphthalen-2-ylimino)-ethyl]-6-methyl-pyran-2one $\left(\mathrm{L}_{1}\right)$ is synthesized using the condensation method and characterized by X-ray diffraction spectroscopy (XRD). The compound obtained is a mono-crystal. The study of its inhibitory efficiency with respect to the corrosion of mild steel in reinforced concrete was realized using the potentiodynamic polarization and impedance spectroscopy (EIS) as electrochemical methods. The inhibition power of this Schiff base against the corrosion of mild steel in concrete is studied in the aggressive medium $0.5 \mathrm{M}$ $\mathrm{NaCl}$ as a function of the concentration of the inhibitor, immersion time and temperature. High inhibition power $90 \%$ is determined for the low concentration $10^{-6} \mathrm{M}$ at $\mathrm{t}=28$ days and $\mathrm{T}=30^{\circ} \mathrm{C}$. This inhibition increases as a function of temperature. The thermodynamic study was used to identify the mechanism of inhibitory action of $\mathrm{L}_{1}$. The inhibiting power (EI\%) and the apparent activation energy (Ea) have been calculated at different concentrations of $\mathrm{L}_{1}$. The values of $\Delta \mathrm{G}_{\mathrm{ads}}, \mathrm{E}_{\mathrm{a}}, \Delta \mathrm{H}_{\mathrm{a}}$, and $\Delta \mathrm{S}_{\mathrm{a}}$ showed that $\mathrm{L}_{1}$ is a good inhibitor of corrosion of the rebar in concrete in an environment of $0.5 \mathrm{M} \mathrm{NaCl}$. The inhibitor studied follows a chemisorption process. The adsorption behavior of this product obeys to Langmuir isotherm. The electrochemical results were confirmed with scanning electron microscopy (SEM). The quantum chemical parameters determined by theoretical calculations were used to elucidate the relationship between inhibiting effect of $L_{1}$ and its molecular structure.
\end{abstract}

Keywords: Corrosion, Concrete, Inhibitor, Schiff bases, XRD, EIS, SEM, DFT.

\section{FULL TEXT}


(C) 2018 The Authors. Published by ESG (www.electrochemsci.org). This article is an open access article distributed under the terms and conditions of the Creative Commons Attribution license (http://creativecommons.org/licenses/by/4.0/). 